\title{
Clinical Study: Change in Outlook Towards Birth After a Midwife Led Antenatal Education Programme Versus Hypnoreflexogenous Self-Hypnosis Training for Childbirth
}

\author{
Klinische Studie: Veränderung der mütterlichen Einstellung auf die Geburt durch einen Hebammen-geführten \\ Geburtsvorbereitungskurs im Vergleich mit der hypnoreflexogenen Geburtsvorbereitung
}

Authors

Affiliations
L. A. Streibert ${ }^{2}$, J. Reinhard ${ }^{1}$, J. Yuan ${ }^{2}$, S. Schiermeier ${ }^{3}$, F. Louwen ${ }^{2}$

1 St. Marienkrankenhaus, Frauenklinik, Frankfurt

${ }^{2}$ Johann Wolfgang Goethe-University Frankfurt am Main, Faculty of Medicine, Department of Obstetrics and Gynaecology,

Frankfurt am Main

${ }^{3}$ University Witten/Herdecke, Marien-Hospital Witten, Witten

\section{Key words}

- childbirth education

- pregnancy education

- birth

childbirth fear

- hypnosis

Schlüsselwörter

- Geburtsvorbereitung

- Geburt

- Geburtsangst

- Hypnose

\section{Abstract \\ $\nabla$}

Aim: To compare the change of maternal outlook towards birth due to a midwife led antenatal education programme versus hypnoreflexogenous self-hypnosis training for childbirth.

Method: Before beginning of the classes and after the last class maternal perception on birth was evaluated using Osgood semantic differential questionnaire. The Gießen personality score was evaluated once.

Results: 213 patients were enrolled in this study. 155 were in the midwife led education programme and 58 in the self-hypnosis training programme. There was no statistically significant difference between the two groups in regard of participants' characteristics, Gießen personality score and initial Osgood semantic differential scores. After the midwife led course childbirth was emotionally more negatively scored (displeasure, tarnishing, dimension evaluation $[\mathrm{p}<0.05]$ ), whereas after the hypnosis course childbirth was emotionally more positively evaluated (pleasure, harmony, dimension evaluation [p $<0.01]$ and brightness [ $<<0.05]$ ).

Summary: In this study hypnoreflexogenous selfhypnosis training resulted in a positive maternal outlook towards childbirth, in comparison to the midwife led course. Further prospective randomised studies are required to test these initial results.

\section{Zusammenfassung \\ $\nabla$}

Ziel: Vergleich der Veränderung der mütterlichen Einstellung zur Geburt anhand von Hebammengeführten Geburtsvorbereitungskursen oder hypnoreflexogenem Training zur Geburtsvorbereitung.

Methode: Zu Beginn und nach Beendigung der Kurse wurde die mütterliche Einstellung zur Geburt unter Zuhilfenahme des Osgood-Ertel-Eindrucksdifferenzials gemessen. Der Gießen-Test zur Persönlichkeitsbeurteilung wurde einmalig angewendet.

Ergebnisse: 213 Frauen waren in die Studie eingeschlossen. 155 davon nahmen an Hebammengeführten Kursen teil und 58 bekamen hypnoreflexogenes Training. Es waren zu Beginn der Kurse keine statistisch signifikanten Unterschiede feststellbar in Bezug auf die Charakteristiken der Teilnehmerinnen, im Gießen-Test und in den Ergebnissen des Osgood-Ertel-Eindrucksdifferenzials. Nach der Hebammen-geführten Geburtsvorbereitung wurde die Geburt negativer wahrgenommen (Freudlosigkeit, Trübung, Valenzdimension $[p<0,05])$, während die Geburt nach dem Hypnosetraining emotional positiver bewertet wurde (Freude, Harmonie, Valenzdimension $[\mathrm{p}<0,01]$ und Helligkeit $[\mathrm{p}<0,05])$.

Zusammenfassung: Hypnoreflexogenes Selbsthypnosetraining zur Geburtsvorbereitung scheint stärkere und positivere mütterliche emotionale Veränderungen in Bezug auf die Einstellung zur Geburt auszulösen als konventionelle Hebammen-geführte Geburtsvorbereitungskurse. Weitere prospektive randomisierte Studien sind nötig, um diese Ergebnisse zu überprüfen.

Correspondence

Priv-Doz. Dr. med. Joscha

Reinhard, MBBS BSc(Hon)

St. Marienkrankenhaus

Frauenklinik

Richard-Wagner-Straße 14

60318 Frankfurt am Main

Joscha.Reinhard@kgu.de 


\section{Introduction}

\section{$\nabla$}

In most high-income countries birth preparation courses are embedded in current health-care practices [1]. Antenatal education programmes have a wide range of aims, such as ways to cope with pain and stress during childbirth, increasing women's confidence for childbirth [2]. Main reasons for women to take part are to get information on physiological changes during pregnancy, reduce anxiety, and include discussions on various options and complications during childbirth [3]. Only a few studies have assessed the effectiveness of antenatal education programmes. A Cochrane systematic review showed no consistent effect of these courses, but only a tendency towards a better knowledge, confidence, and competence was identified in small studies [4]. Most health professionals recommend the courses [3], even though aims, content and processes of antenatal education vary considerably [5]. Evaluation of antenatal courses is difficult since widely adopted standards or guidelines are missing $[5,6]$.

Artieta-Pinedo et al. [7] identified decreased anxiety in women attending antenatal education compared with non-attenders. Similarly, Paz-Pascuale et al. [8] also found decreased anxiety in women who attended courses compared to women not attending.

Hypnosis has been used in various clinical settings including childbirth [9-14] and external cephalic version $[15,16]$ and the fear of patients prior to surgery has also been reduced using hypnosis $[17,18]$. Hypnosis may have a positive influence on maternal and neonatal outcomes, such as labour pain, duration of birth, complications and postpartum depression, but recent randomised controlled trials did not show an effect [19-26].

The overall aim of this study was to investigate the change in outlook towards birth after conventional preparation courses in comparison to hypnoreflexogenous self-hypnosis. The change of the maternal emotional state was evaluated using the Osgood semantic differential score.

\section{Materials and Methods}

$\nabla$

This study is a cohort study of pregnant women, who freely chose either midwife led antenatal birth preparation classes or hypnoreflexogenous self-hypnosis training for childbirth October 2009 to January 2010.

\section{Course design}

The midwife led classes were done by three different senior midwives (work experience over 10 years [midwife A, B \& C]). The maximum number of women allowed in the birth preparation group was 12 women. A sub-group analysis was also carried out between the midwife groups. The 10 times 2-hour-sessions had mainly informational content concerning the pregnancy, the birth and the newborn child. As well as the communication with other expectant mothers, the course units comprised exercises for body perception and breathing exercises as coping techniques for labour. The hypnoreflexogenous self-hypnosis training was carried out by a doctor qualified in hypnosis (JR). The maximum number of women allowed in the hypnosis course was 8 women. In four 2-hour-sessions women in their last trimester of pregnancy were taught self-hypnosis techniques. In hypnotic trance the birthing process was imagined. This method is based on three principles:
1. negative conditioned terms were substituted through neutral terms,

2. the level of tension is reduced through hypnotic trance and

3. the self-confidence and the reliance of the expectant mother is reinforced [10].

After the second session a CD with the taught hypnotherapy intervention was given for home use.

\section{Participants}

Women were eligible to take part in the study if they were pregnant, German-speaking, at least 18-years-old and for the selfhypnosis course the women had to be above 26th gestational age. Participants were included in the trial after return of a completed baseline questionnaire and provision of consent. Ethical approval was given by the local ethics committee.

\section{Outcome and data collection}

The Osgood semantic differential score [27-29] is a validated questionnaire, which has been modified by Ertel and can be used to quantify emotional changes [30-32]. On a list of bipolar scales the participants had to score from -3 to +3 with a middle or neutral point. For measurement of attitudes the semantic differential is nowadays one of the most widely used scales. Three recurrent attitudes have been identified: Firstly, the "good - bad" adjective defines the evaluation. Secondly, the potency loads highest on the adjective pair "strong - weak". Thirdly, the activity factor defines the adjective pair "active - passive". These dimensions were found to be cross-cultural [29-31]. Before the first class and after the last course unit the Osgood semantic differential questionnaire was evaluated for the four words: "birth, baby, partner, hypnosis". The word birth was chosen due to the fact that the birth preparation course should positively chance the view towards birth. Similarly the word baby might be changed due to the course. The word partner was chosen as a reference since this would be unlikely to be changed due to the intervention. Hypnosis was chosen due to the fact that this was one of the interventions evaluated in this study. Using the Gießen questionnaire [33] a screening for psychological disorders was carried out. This also enabled us to evaluate the different cohort groups for personality differences. The dimension activity, evaluation and potency are the mean value of all factors in that group, respectfully (see - Fig. 1 a to $c$ ).

\section{Statistical analysis}

The data analysis used SPSS (Version 21, IBM@ SPSS@ Statistics). Differences between groups were tested by a non-parametric Mann-Whitney test. Two-sided p-values were reported for all tests and a value $<0.05$ was regarded as significant.

\section{Ethics approval}

Ethics approval was granted by the local university of Witten/ Herdecke ethics committee.

\section{Results \\ $\nabla$}

213 participants were enrolled in this study. 155 had midwife led education programme and 58 had self-hypnosis training. Due to the small number of participants for midwife group $C(n=8)$ no subgroup analysis was carried out. There was no statistically significant difference between the two groups in regard of participants' characteristics (age, school education level, university 
master degree, parity, pregnancy complications, premature labour contractions [ $\bullet$ Table 1 ]), Gießen personality score ( $\bullet$ Table 1) and initial Osgood semantic differential scores. Similarly, no difference was identified in the two midwife led education programmes (midwife A and B) ( $\bullet$ Table $\mathbf{1}$ ).

\section{Midwife courses}

Overall the participants of the midwife led courses $(n=155)$ had a statistically significant change for the word "birth" only for the dimension evaluation (more negative outlook; $\mathrm{p}<0.05$; 0 Fig. 1 ). For the word "baby" the dimension activity ( $p<0.01)$, evaluation $(\mathrm{p}<0.05)$ and potency $(\mathrm{p}<0.05)$ were statistically significant differences detected ( $\bullet$ Fig. 1). Similarly, for the word "partner" the dimension activity $(\mathrm{p}<0.01)$ and potency $(\mathrm{p}<0.05)$ were different. No difference was found for the word "hypnosis" ( $\bullet$ Fig. 1). There were no statistically significant differences on the semantic differential scores of midwife A and B. For the word "birth" the midwife A group $(n=113)$ had a statistically significant change towards arousal $(\mathrm{p}<0.01)$, displeasure $(\mathrm{p}<0.05)$ and tarnishing $(\mathrm{p}<0.05)$. Group A had a positive change (bad outlook into birth) in dimension evaluation $(p<0.05)$ and indulgence $(p<0.05)$ ( Fig. 2). For "birth" the midwife B group $(n=34)$ only had one statistically significant change towards quickness $(p<0.05$; ๑ Fig. 2).

\section{Hypnosis courses}

For the hypnosis group all dimensions were highly statistically significant different ( $\mathrm{p}<0.01$ ) apart from the word "baby" the dimension potency and for the word "hypnosis" the dimension activity ( Fig. 1). The hypnosis CD was listened to at least twice a week (mean $2.5 \pm$ standard deviation 1.8 ).

For the hypnosis group $(n=58)$ highly significant changes $(\mathrm{p}<0.01)$ were identified towards movement, noise, arousal, negative change (more activity) in dimension activity, pleasure, harmony, negative change (i.e. positive outlook into birth) in dimension evaluation, emphasis, fortitude, strength, negative change (i.e. positive outlook into birth) in dimension potency for the word "birth". Similarly, in the hypnosis group for the scales allegro and brightness statistically significant changes were seen ( $\mathrm{p}<0.05$; 0 Fig. 2 ).

\section{Discussion \\ $\nabla$}

For the first time this study demonstrates the change in emotional outlook towards birth in women after midwife led preparation courses and hypnoreflexogenous self-hypnosis training using Osgood semantic differential score. Even though the midwife led courses had a longer duration, the women's emotional change was less marked in comparison to the hypnosis course. For the midwife courses the emotional change in regard to "birth" is in the wrong direction. The women had a statistically significant change towards the unwanted polarity (displeasure, tarnishing, dimension evaluation; $\mathrm{p}<0.05$ ), whereas in the hypnosis group the participants had a change towards the wanted polarity (pleasure, harmony, dimension evaluation $(p<0.01$ and brightness $\mathrm{p}<0.05$ ). These differences cannot be explained by differences in personality dimensions in the two groups (Gießen test $\mathrm{p}>0.05$ ). Between the two largest midwife course groups there also was no difference found in the polarity direction. The natural birth approach aims to decrease muscle tension, which is induced by fear and leads to labour pains [1,34]. Training in relaxation and

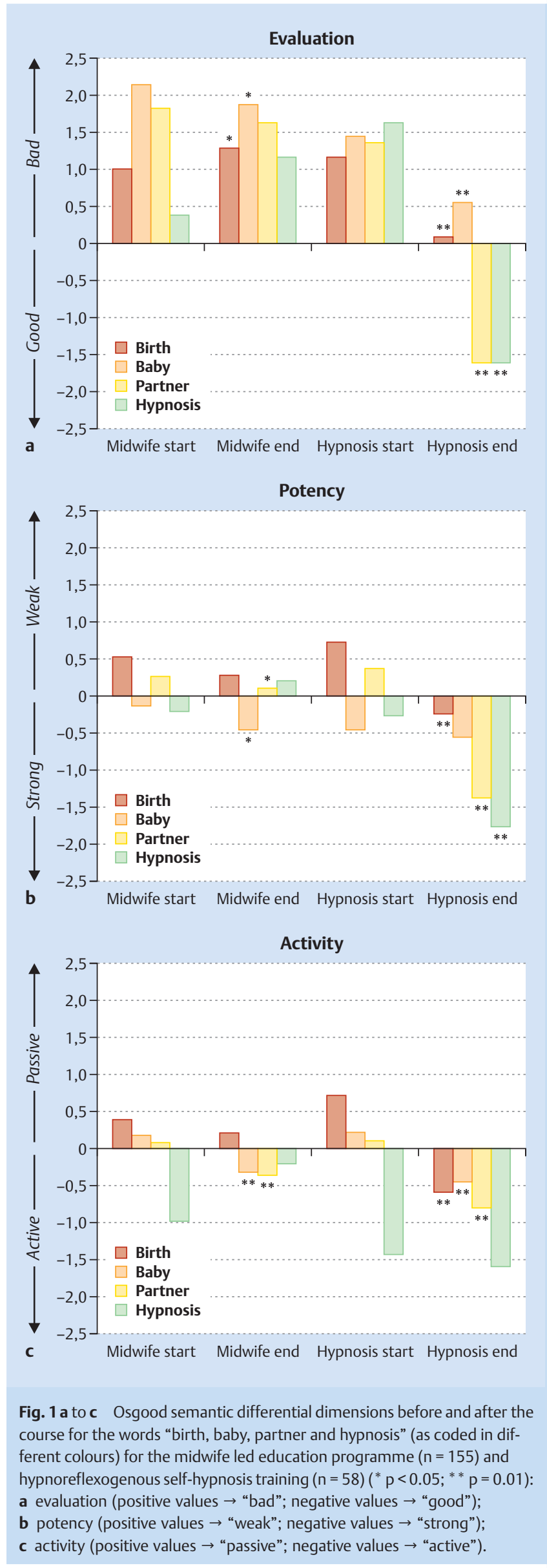



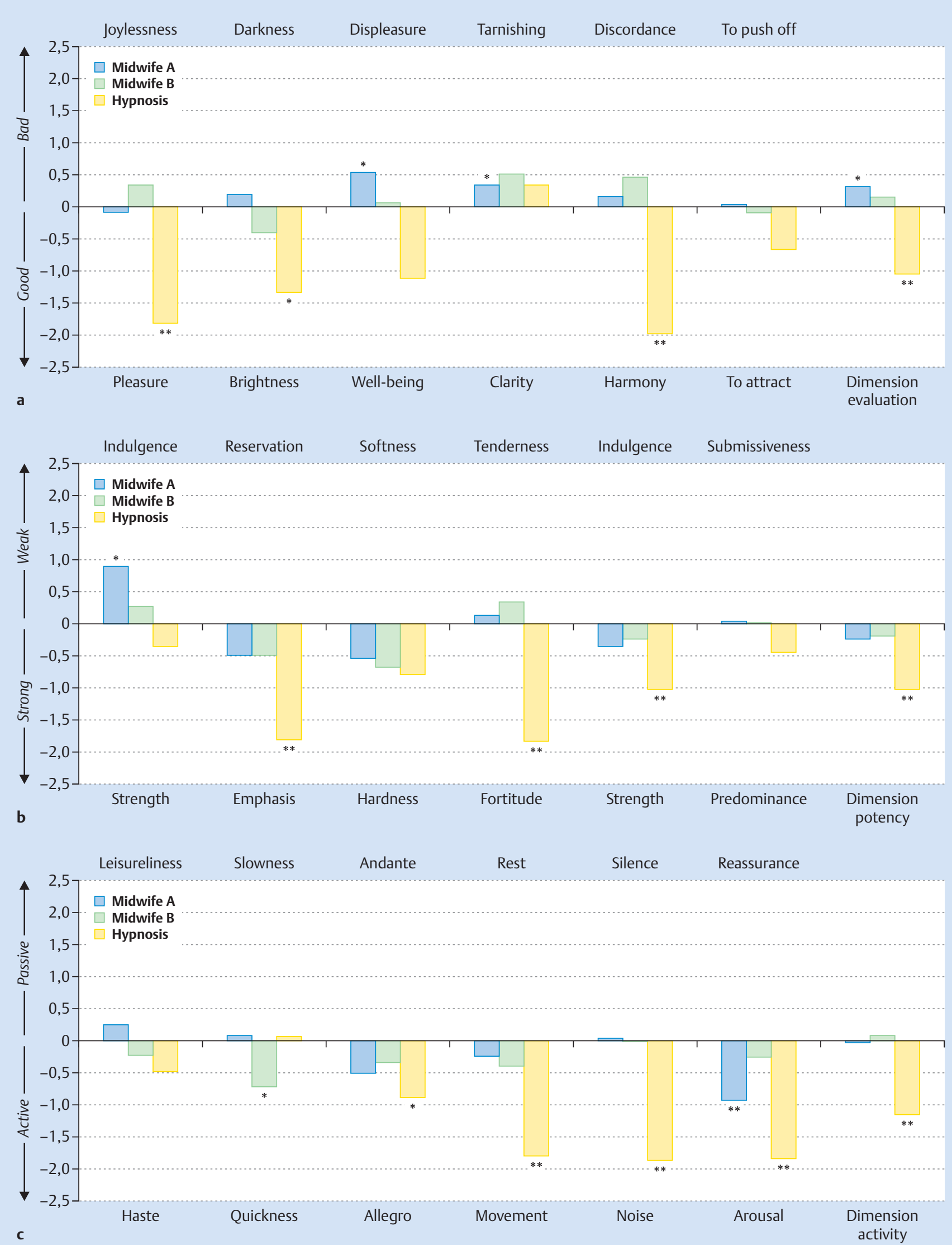

Fig. 2a to c Change of Osgood semantic differential scales word "birth" (after the course score - at the beginning) for midwife $A(n=113)$, midwife

B $(n=34)$ and hypnosis $(n=58)$ : a dimension evaluation, $\mathbf{b}$ dimension potency and $\mathbf{c}$ dimension activity $\left({ }^{*} \mathrm{p}<0.05 ;{ }^{* *} \mathrm{p}<0.01\right)$. 
Table 1 Baseline characteristics of the study population for midwife A $(n=113)$, midwife $B(n=34)$ and hypnosis group $(n=58)(n$. s. $=$ no statistically significant difference, $p>0.05$ ).

\begin{tabular}{|c|c|c|c|c|}
\hline & Midwife A & Midwife B & Hypnosis & p-value \\
\hline \multicolumn{5}{|l|}{ Maternal age (years) } \\
\hline$\checkmark \leq 25$ & 16.1 & 11.8 & 7.4 & n.s. \\
\hline - $26-29$ & 24.1 & 23.5 & 22.2 & n.s. \\
\hline$>30-35$ & 39.3 & 29.4 & 44.4 & n.s. \\
\hline$\geq 36$ & 20.5 & 35.3 & 25.9 & n.s. \\
\hline \multicolumn{5}{|l|}{ School education } \\
\hline - A-levels & 61.3 & 57.7 & 62.5 & n.s. \\
\hline - Technical diploma & 21.3 & 30.8 & 20.8 & n.s. \\
\hline - Secondary modern school & 17.5 & 11.5 & 16.7 & n.s. \\
\hline - University (master) degree & 40.5 & 34.6 & 41.3 & n.s. \\
\hline Born in Germany & 93.8 & 100 & 83.7 & n.s. \\
\hline Expecting first child & 70.2 & 66.7 & 68.8 & n.s. \\
\hline At least one (missed) abortion & 8.3 & 11.1 & 25 & n.s. \\
\hline Pregnancy without complications & 94.0 & 88.9 & 89.5 & n.s. \\
\hline Premature labour contractions & 20.2 & 23.1 & 15.6 & n.s. \\
\hline Premature labour before 34th gestation age & 52.9 & 50 & 100 & n.s. \\
\hline \multicolumn{5}{|l|}{ Gießen test } \\
\hline Social resonance & $4.79 \pm 0.77$ & $4.65 \pm 0.67$ & $4.42 \pm 1.02$ & n.s. \\
\hline Dominance & $4.29 \pm 0.71$ & $4.23 \pm 0.73$ & $4.27 \pm 0.72$ & n.s. \\
\hline - Control & $4.53 \pm 0.66$ & $4.03 \pm 0.76$ & $4.13 \pm 0.78$ & n.s. \\
\hline - Prevailing mood & $4.19 \pm 0.91$ & $4.07 \pm 0.81$ & $4.22 \pm 0.66$ & n.s. \\
\hline Penetrability & $3.48 \pm 0.85$ & $3.28 \pm 0.82$ & $3.77 \pm 1.16$ & n.s. \\
\hline - Social ability & $3.01 \pm 0.78$ & $3.07 \pm 0.67$ & $3.63 \pm 1.36$ & n.s. \\
\hline
\end{tabular}

education of the physiological process of labour is intended to reduce fear and tension and as a consequence mothers should experience less labour pain [1]. Lamaze [35] introduced relaxation as a conditioned response to labour contractions, which includes various breathing techniques to interfere with the pain signal transmission from the uterus to the brain and improve oxygenation.

Emotional reactions have also been shown to influence pain experience $[24,36]$. High levels of fear, anxiety and emotional stress are important factors in a woman's experience of childbirth pain $[24,37,38]$, which may result in postpartum depression, posttraumatic stress syndrome, future caesarean section or a reluctance to have more children [24,39-42]. These study results demonstrate that the outlook towards birth can be influenced by a midwife and hypnosis course. A higher impact has been seen during the hypnosis course, where the women's outlook onto birth was statistically significantly positive (dimension evaluation; $\mathrm{p}<0.01$ ), stronger (dimension potency $\mathrm{p}<0.01$ ) and more active (dimension activity; $\mathrm{p}<0.01$ ) after completion of the hypnosis course. For the midwife led courses only the dimension potency was changed ( $p<0.05$ ), however the women's Osgood semantic differential score was worse (i.e. towards "bad"). Further investigations are required as to why the midwife led courses showed negative outlook towards birth. These study results are consistent with previous study on hypnoreflexogenous birth preparation in the perception of birth and quicker convalescence time [10].

As expected, there was a large positive change in the women's emotional score of "hypnosis" in the hypnosis group (pleasure, harmony, dimension evaluation $[\mathrm{p}<0.01]$ and brightness $[p<0.05]$ ), whereas in the midwife led courses no differences were detected in all factors. Nowadays there are still large reservations and false beliefs with regard to hypnotherapy even though hypnotherapy has been certified as an effective psychotherapy in Germany.

The limitation of this study lies in the factor that the study design is only a prospective cohort study, which tried to exclude a personality bias of birth preparation course via the Gießen personality test. Furthermore the differences in midwife course sizes have been evaluated on the ground whether there are any statistically significantly differences between the groups. Obviously, these results do not demonstrate that the women do have less birth pain during labour and only show the outlook i.e perception before birth. Further prospective randomised controlled trials are required to test these initial findings and evaluate birth outcomes.

\section{Conclusion \\ $\nabla$}

Hypnoreflexogenous self-hypnosis training seems to induce larger and more positive maternal emotional changes towards the outlook to birth in comparison to midwife led courses if women choose self-hypnosis deliberately. Further prospective randomised studies are required to test these initial results.

\section{Contribution to Authorship}

JR designed the trial. LAS was responsible for the data collection. JR and LAS performed the data analysis. JR wrote the first draft. All authors edited the manuscript and agreed on the final version. JR is guarantor.

\section{Funding \\ $\nabla$}

None. 


\section{Acknowledgements}

$\nabla$

We would like to thank all midwives for participating and support of the study. We wish to thank all the women who took part in the project.

\section{Conflict of Interest \\ $\nabla$}

The authors stated that there are no conflicts of interest regarding the publication of this article.

\section{References}

1 Jaddoe VWV. Antenatal education programmes: do they work? Lancet 2009; 374: 863-864

2 Dave T, Johnson D, Ingram J. Transition to parenthood: the needs of parents in pregnancy and early parentood. BMC Pregnancy Childbirth 2008; $8: 30$

3 Fabian HM, Radestad IJ, Waldenstroem U. Childbirth and parenthood education classes in Sweden: women's opinion and possible outcomes. Acta Obstet Gynecol Scand 2005; 84: 436-443

4 Gagnon AJ, Sandall J. Individual or group antenatal education for childbirth or parenthood, or both. Cochrane Database Syst Rev 2007; 3: CD002869

5 O'Meara CM. Childbirth and parenting education - the providers' viewpoint. Midwifery 1993; 9: 76-84

6 Bergström $M$, Kieler $H$, Waldenström $U$. Effects of natural childbirth preparation versus standard antenatal education on epidural rates, experience of childbirth and parental stress in mothers and fathers: a randomised controlled multicentre trial. BJOG 2009; 116: 1167-1176

7 Artieta-Pinedo I, Paz-Pascual C, Grandes G et al. The benefits of antenatal education for the childbirth process in Spain. Nurs Res 2010; 59: 194-202

8 Paz-Pascual C, Artieta Pinedo I, Grandes G et al. Design and process of the EMA cohort Study: the value of antenatal education in childbirth and breastfeeding. BMC Nurs 2008; 7: 5

9 Schauble PG, Werner WE, Rai SH et al. Childbirth preparation through hypnosis: the hypnoreflexogenous protocol. Am J Clin Hypn 1998; 40: 273-283

10 Reinhard J, Hüsken-Janssen H, Schiermeier S. [Childbirth preparation through the hypnoreflexogenous protocol developed by Schauble]. Z Geburtshilfe Neonatol 2007; 211: 162-164

11 Reinhard J, Hüsken-Janßen H, Hatzmann H et al. Hypnotherapie, Gestationsalter und Frühgeburtenrate. Z Geburtsh Neonatol 2010; 214: 8287

12 Reinhard J, Hüsken-Janßen H, Hatzmann H et al. Hypnotherapie bei vorzeitiger Wehentätigkeit. Geburtsh Frauenheilk 2008; 68: 603-606

13 Reinhard J, Hüsken-Janßen H, Hatzmann H et al. Evidenzbasierte Hypnotherapie bei Krebspatienten. KIM 2008; 49: 7-12

14 Reinhard J, Roesler R, Yuan J et al. Prostaglandin E2 labour induction with intravaginal (Minprostin ${ }^{\circledR}$ ) versus intracervical (Prepidil ${ }^{\circledR}$ ) at term: randomized study of maternal and neonatal outcome and patient's perception using the Osgood semantic differential scales. BioMed Research International 2014; DOI: http://dx.doi.org/10.1155/ 2014/682919. Online: http://www.hindawi.com/journals/bmri/2014/ 682919/; Stand: 16.11 .2015

15 Reinhard J, Heinrich TM, Reitter A et al. Clinical hypnosis before external cephalic version. Am J Clin Hypnos 2012; 55: 184-192

16 Reinhard J, Peiffer S, Sänger $N$ et al. The Effects of Clinical Hypnosis versus Neurolinguistic Programming (NLP) before External Cephalic Version (ECV): A Prospective Off-Centre Randomised, Double-Blind, Controlled Trial. Evid Based Complement Alternat Med 2012; DOI: $10.1155 / 2012 / 626740$
17 Montgomery GH, David D, Winkel G et al. The effectiveness of adjunctive hypnosis with surgical patients: a meta-analysis. Anesth Analg 2002; 94: 1639-1645

18 Montgomery GH, Weltz CR, Seltz M et al. Brief presurgery hypnosis reduces distress and pain in excisional breast biopsy patients. Int J Clin Exp Hypn 2002; 50: 17-32

19 Werner A, Uldbjerg N, Yachariae R et al. Antenatal hypnosis training and childbirth experience: a randomized controlled trial. Birth 2013; 40: 272-280

20 Mehl-Madrona LE. Hypnosis to facilitate uncomplicated birth. Am J Clin Hypn 2004; 46: 299-312

21 Freeman RM, Macaulay AJ, Eve L et al. Randomised trial of self hypnosis for analgesia in labour. Br Med J 1986; 292: 657-658

22 Cyna AM, Andrew MI, McAuliffe GL. Antenatal self-hypnosis for labour and childbirth: a pilot study. Anaesth Intensive Care 2006; 34: 464469

23 Mairs DAE. Hypnosis and pain in childbirth. Contemporary Hypnosis 1995; 12: 111-118

24 Cyna A, Crowther C, Robinson J et al. Hypnosis antenatal training for childbirth: a randomised controlled trial. BJOG 2013; 120: 1248-1259

25 Werner A, Uldbjerg $N$, Zachariae $R$, et al. Self-hypnosis for coping with labour pain: a randomised controlled trial. BJOG 2013; 120: 346-353

26 Werner A, Uldbjerg $N$, Zachariae R et al. Effect of self-hypnosis on duration of labor and maternal and neonatal outcomes: a randomized controlled trial. Acta Obstet Gynecol Scand 2013; 92: 816-823

27 Osgood CE, Suci GJ, Tannenbaum PH. The Measurement of Meaning. Urbana: University of Illinois Press; 1957

28 Ertel S. Standardisierung eines Eindrucksdifferentials. Z exp angew Psychol 1965; 12: 22-58

29 Ertel S. Weitere Untersuchungen zur Standardisierung eines Eindrucksdifferentials. Z exp angew Psychol 1965; 12: 177-208

30 Zahler E. Frei improvisierte Musik in der Musiktherapie als Medium für Ausdruck und Kommunikation von Emotionen. Eine musikpsychologische Studie zur musiktherapeutischen Grundlagenforschung. Deutsche Gesellschaft für Musiktherapie 2006; Berlin. Online: http:// www.musiktherapie.de/fileadmin/user_upload/medien/pdf/mu_ downloads/zahler_frei-improvisierte-musik.pdf; Stand: 16.11.2015

31 Windemuth D, Stücker M, Altmeyer P. Implizite Persönlichkeitstheorien in der Dermatologie. Hautarzt 2000; 51: 176-181

32 Badia A, Meneses J, Monereo C. Affective dimension of university professors about their teaching: an exploration through the semantic differential technique. Universitas Psychologica 2014; 13: 161-173

33 Beckmann D, Brähler E, Richter H. Der Gießen-Test (GT). 4. Aufl. Göttingen: Hogrefe (Vorm. Verlag Hans Huber); 1990

34 Dick-Read G. Childbirth without Fear: the Principles and Practice of natural Childbirth. New York, London: Harper and Brothers Publishers; 1994

35 Lamaze F. Painless Childbirth: psychoprophylactic Method. London: Burke; 1958

36 Lowe NK. The pain and discomfort of labour and birth. J Obstet Gynecol Neonatal Nurs 1996; 25: 82-92

37 Waldenstrom $U$. Experience of labor and birth in 1111 women. J Psychosom Res 1999; 47: 471-482

38 Waldenstrom $U$, Borg IM, Olsson B et al. The childbirth experience: a study of 295 new mothers. Birth 1996; 23: 144-153

39 Gottval K, Waldenstrom U. Does a traumatic birth experience have an impact on future reproduction? BJOG 2002; 109: 254-260

40 Creedy DK, Shochet IM, Horsfall J. Childbirth and the development of acute trauma symptoms: incidence and contributing factors. Birth 2000; 27: 104-111

41 Saisto T, Halmesmaki E. Fear of childbirth: a neglected dilemma. Acta Obstet Gynecol Scand 2003; 82: 201-208

42 Waldenstrom U, Hildingsson I, Ryding EL. Antenatal fear of childbirth and its association with subsequent caesarean section and experience of childbirth. BJOG 2006; 113: 638-646 